\title{
La evolución del modelo de desarrollo humano integral desde la Populorum progressio en diálogo interdiscipli- nar con otras escuelas de desarrollo
}

\author{
José María Larrú Ramos'
}

Resumen: El trabajo caracteriza la "escuela católica de desarrollo" con los siguientes ochos rasgos identitarios: trascendente-vocacionado, humano, integral, solidario, caritativo-verdadero, igualador, endógeno y sostenible. Además se destacan los siguientes elementos diferenciales respecto a otras escuelas: en la dimensión política, el ejercicio del poder como servicio, la participación de la sociedad civil para lograr un bien común promovido por el Estado bajo el principio de subsidiariedad y la posibilidad de que una autoridad supranacional fuera el garante de los "bienes comunes globales" (LS 174) contenidos en la Agenda 2030 del Desarrollo Sostenible; en la dimensión económica, la lógica del don, el trabajo subjetivo, el emprendimiento y la obligación de ayudar a los países menos desarrollados; en la dimensión sociocultural, la opción preferencial por los pobres, las estructuras de pecado y el ejercicio de la caridad política; en la dimensión ecológica, la "ecología integral" y la "conversión ecológica", a la luz de la encíclica Laudato si'.

Palabras clave: Desarrollo humano, persona, religión, integralidad, Agenda 2030 de desarrollo sostenible.

Fecha de recepción: $28-30$ de junio de $2017^{2}$.

Fecha de admisión definitiva: 21 de junio de 2018.

\footnotetext{
' Universidad CEU San Pablo.

${ }^{2}$ Fecha de celebración del Simposio.
} 
The evolution of the integral human development model since the Populorum Progressio in interdisciplinary dialogue with other development schools

Abstract: The article characterizes the "Catholic school of development" with the following eight identity traits: transcendent-vocational, human, integral, solidary, charitable-true, equalizer, endogenous and sustainable. The following differential elements are also highlighted in relation to other schools: in the political dimension, the exercise of power as a service, the participation of civil society to achieve a common good promoted by the State under the principle of subsidiarity and the possibility that a supranational authority will be the guarantor of the "global commons" (LS 174) contained in the 2030 Agenda for Sustainable Development; in the economic dimension, the logic of the gift, subjective work, entrepreneurship and the obligation to help the least developed countries; in the sociocultural dimension, the preferential option for the poor, the structures of sin and the exercise of political charity; in the ecological dimension, the "integral ecology" and the "ecological conversion", in the light of the encyclical Laudato si'.

Key words: Human development, person, religion, integrality, Agenda 2030 for sustainable development.
L'évolution du modèle de développement humain intégral depuis la Populorum Progressio en dialogue interdisciplinaire avec d'autres écoles de développement

Résumé: Ce travail décrit «l'école catholique de développement» avec les huit caractères identitaires suivants: transcendent-vocationnel, humain, intégral, solidaire, caritatif-véritable, égaliseur, endogène et durable. De plus, les éléments différentiateurs par rapport aux autres écoles sont mis en avant: 1) dans la dimension politique, I'exercice du pouvoir comme service, la participation de la société civile pour atteindre un bien commun promu par l'État sous le principe de subsidiarité, et la possibilité qu' une autorité supranationale soit la garante des «biens communs globaux» (LS 174), contenus dans l'Agenda 2030 du Développement Durable; 2) dans la dimension économique, la logique du don, du travail subjectif, de l'entreprise etl'obligation d'aider les pays les moins développés; 3 ) dans la dimension socioculturelle, l'option préférentielle pour les pauvres, les structures de péché et l'exercice de la charité politique; 4) dans la dimension écologique, la "écologie intégrale» et la "conversion écologique», à la lumière de l'encyclique Laudato Si'.

Mots clé: Développement humain, personne, religion, intégralité, Agenda 2030 du développement durable.

\section{Introducción}

El 4 de abril de 2017 el Santo Padre Francisco recibía en audiencia a los participantes en el congreso promovido por el Dicasterio para el Servicio del Desarrollo Humano Integral, con motivo del 50 aniversario de la encíclica Populorum progressio. En su discurso exponía la necesidad de integrar a los diferentes pueblos, a sus sistemas (la economía, las finanzas, el trabajo, la cultura, la vida familiar, la religión), la dimensión individual y la comunitaria del desarrollo, el cuerpo y el 
alma de cada persona, donde el hombre y Dios no se enfrenten como contrarios, sino que sean contemplados en unidad, tal como acepta la revelación cristiana que estuvo en las dos naturalezas del Cristo. Terminó su discurso con una apelación al concepto de persona como lo más identificativo del modelo de desarrollo católico:

el concepto de persona, nacido y madurado en el cristianismo, contribuye a perseguir un desarrollo plenamente humano. Porque persona siempre dice relación, no individualismo, afirma la inclusión y no la exclusión, la dignidad única e inviolable y no la explotación, la libertad y no la coacción.

La creación de un Congreso Internacional sobre el Desarrollo Humano en el aniversario de la aportación de Pablo VI en 1967 con la primera encíclica centrada en este tema, así como la creación del Dicasterio para el Desarrollo Humano Integral, pueden ya dar una idea de la importancia y actualidad del tema. El desarrollo humano integral es la concreción, en el ámbito pluridisciplinar de los Estudios del Desarrollo, de las relaciones interpersonales e internacionales dirigidas a crear las condiciones de vida que permitan a cada persona ser y hacer aquellos proyectos vitales que considere razonablemente valiosos. Los dos núcleos en los que podría integrarse toda la Doctrina Social de la Iglesia (DSI a partir de ahora), son la dignidad de la persona y el modelo de sociedad derivado de ella. Ambos, han sido revelados en Cristo por el Espíritu Santo y ambos deben ser contemplados en cualquier modelo de desarrollo integral. El presente trabajo aborda, así, un aspecto de gran centralidad teológica y actualidad.

En septiembre de 2015, Naciones Unidas aprobaba en su Asamblea General, la Agenda 2030 del Desarrollo Sostenible, especificando 17 Objetivos de Desarrollo Sostenible (ODS). Eran la continuidad de la Declaración del Milenio de 2000 y los Objetivos de Desarrollo del Milenio, uniendo en un solo documento las agendas del desarrollo y de la sostenibilidad ambiental (Naciones Unidas 2015a). El itinerario de las relaciones internacionales va a quedar marcado por esta Agenda, pero en este tipo de documentos quedan exentos los debates sobre la ética y la antropología asociadas a los modelos de desarrollo. Precisamente son éstas las aportaciones más significativas que puede hacer la DSI. De ella no debe esperarse ni propuestas técnicas específicas, ni una "tercera vía" entre un modelo de desarrollo más capitalista o más socialista (SRS 41$)^{3}$. No es ese el estatuto epistemológico adecuado para valorar las orientaciones propuestas por la DSI, que hace sus aportaciones desde el ámbito de la Teología Moral que comprende principios de acción y normas de juicio abiertas a la heterogeneidad de los contextos históricos, culturales y espaciales (OA 4; SRS 3, 8, 41). Es por ello que, en este estudio, no se pretende,

${ }^{3}$ En este documento se asumen las siglas de uso más frecuente en la DSI. 
de ninguna manera, que los elementos seleccionados como nucleares en lo que podría denominarse una "escuela católica de desarrollo" sean éstos y ningún otro más. La DSI permite la existencia de diversas concreciones en las políticas de desarrollo, en los enfoques económicos y empresariales y debe adaptarse a las diferentes culturas.

Hay corrientes actuales más cercanas a los principios y orientaciones de la "escuela católica", como el paradigma del desarrollo humano (PNUD 2016), el capability approach (de Sen 1999 o Nussbaum 2012), la economía civil (Zamagni 2014) o la de comunión (Bruni 2001). Pero ninguna agota la riqueza doctrinal del mensaje social cristiano. Otros enfoques alternativos no parecen en principio incompatibles con las orientaciones de la DSI, aunque sus propuestas pueden considerarse algo más parciales como la economía circular (Balboa \& Somonte 2014, Comisión Europea 2015), la colaborativa (Sundararajan 2017), la economía verde (Webster 2016) y la azul (Pauli 2011 ) o las empresas del bien común (Felber 2012). Incluso podrían identificarse ciertas semejanzas y coincidencias con la corriente del Buen Vivir andino (Acosta 2013; Braña 2016) en su propuesta de desarrollarse viviendo en armonía con uno mismo, con los demás y con la naturaleza, o el decrecimiento (Latouche 2008; Taibo 2009; Unceta 2014) que es citado en LS 193. Una vez más, las orientaciones doctrinales de la Moral Social católica no conducen a una única concreción, pero sí delinean un "modelo" que podría calificarse como "escuela de desarrollo".

Este trabajo se ha inspirado en un artículo académico de Hidalgo (201 1a) en el que identifica siete "escuelas de desarrollo" desde la perspectiva sincrónica de la Economía Política del Desarrollo ${ }^{4}$. A partir de esas escuelas y los elementos iden-

\footnotetext{
${ }^{4}$ Las escuelas son la de la modernidad, la estructuralista, la neomarxista, la neoliberal, la institucionalista, la islámica y la alternativa o altermundista. La de la modernización puso la clave del desarrollo en el cambio estructural y la industrialización; la estructuralista en las relaciones de dependencia mutua, comerciales y culturales; la neomarxista en el intercambio desigual y la emancipación proletaria colectivizando la propiedad de los medios de producción; la neoliberal apuesta por mercados libres donde se maximicen las ganancias mediante el libre comercio internacional manteniendo una macroestabilidad; la institucional estudia cómo las instituciones participativas y no extractivas generan mayor estabilidad política e instituciones económicas eficientes; la islamista trata de reconstruir un califato en el que las relaciones internacionales e interpersonales estén gobernadas por al sharía; las altermundistas forman un heterogéneo núcleo que tiene en común la insuficiencia del ingreso por habitante como medidor del desarrollo y se abre a concepciones amplias e incluso de post-desarrollo y trans-desarrollo. Una clave hermenéutica básica es si se admite que existe una sola teoría económica estándar (neoclásica como hace la escuela de la modernización y la neoliberal) y si es posible o no que el desarrollo beneficie tanto a los países hoy ya ricos como a los que están "en desarrollo" (no lo admiten la neomarxista, la estructuralista y las altermundistas).
} 
titarios que el autor considera en cada una de ellas, se ha formulado la hipótesis general de si -al igual que Hidalgo nombra una escuela islamista de desarrollo- cabe la posibilidad de identificar una "escuela católica de desarrollo". Para abordar esta cuestión tan amplia, se ha procedido a dividir la hipótesis principal en otras secundarias. Así, tras encuadrar el problema y situar el elemento religioso dentro del desarrollo y del discernimiento ético, se subdivide la pregunta en los cuatro componentes más comunes de todo modelo de desarrollo: el político, el económico, el socio-cultural y el ecológico o medioambiental que dan lugar al desarrollo humano sostenible.

Conviene advertir, en primer lugar, que la opción metodológica empleada en este trabajo ha sido la que podríamos denominar "hermenéutica de la circularidad", que combina lo deductivo más propio de la revelación con lo inductivo, más propio de la "autonomía de la realidad" (GS 36) $)^{5}$ que supone un respeto y un diálogo con las aportaciones de las ciencias sociales, especialmente con la economía del desarrollo.

En segundo lugar, merece tenerse en cuenta que el trabajo postula que la religión puede (y debe) formar parte de los factores de desarrollo ya que la idea que la religión tenga sobre la bondad o maldad de, por ejemplo, los bienes materiales y su acumulación, el trabajo, el ahorro y su dedicación en forma de inversión productiva, sobre el emprendimiento y la innovación, incluso sobre la natalidad y el rol de la mujer en la sociedad, influyen de forma determinante en la concepción que esa sociedad tenga de su propio desarrollo (Deneulin \& Bano 2009). Muchas personas incorporan lo religioso a sus vidas y a su idea de bienestar y de felicidad. En las narraciones de experiencias de bienestar y felicidad se incluyen valores y creencias religiosas como la armonía con el Creador, la tranquilidad de ánimo y de conciencia, la felicidad proporcionada por el ejercicio de valores superiores al placer material como el servicio desinteresado, el cuidado de los hijos o acciones de voluntariado. Aunque es cierto que lo religioso ha llegado a ser un "tabú" en los estudios del desarrollo (Ver Veek 2000), se puede apreciar un cambio y un renovado interés por incorporarlo con naturalidad en la multi-dimensionalidad del desarrollo (Selinger 2004; Tomalin 2005; Teer Har \& Ellis 2006, Van Til 2010, entre otros).

El resto del trabajo se organiza de la siguiente manera. En la segunda sección, se describen las características más propias y diferenciales de la propuesta católica para el desarrollo integral. En la tercera sección, se presentan de forma breve al-

\footnotetext{
${ }^{5}$ Tal como propuso la Comisión Teológica Internacional, "la teología católica reconoce los métodos propios de las otras ciencias y los utiliza críticamente en su propia investigación. No se aísla a sí misma de la crítica y da la bienvenida al diálogo científico" (CTI 2012, n 85).
} 
gunas de las claves más importantes en cada dimensión constitutiva del desarrollo: política, económica, sociocultural y ecológica. En la cuarta sección se recogen las conclusiones y futuras líneas de investigación.

\section{Características constitutivas de la escuela católica de desarrollo}

Puede sostenerse, como hipótesis de partida, que la "escuela católica" de desarrollo es la que está inspirada por la Doctrina Social de la Iglesia, surgida a partir de 1891 con la encíclica Rerum novarum (RN) de Leon XIII, a la que han seguido otros papas, y que se ha ocupado del desarrollo desde la aportación de Juan XIII en 1963 con Mater et magista (MM), ampliada con otros documentos entre los que destacan la Populorum progressio (PP) de Pablo VI (1967), Sollicitudo rei sociallis (SRS) de Juan Pablo II (1987), Caritas in veritate (CV) de Benedicto XVI (2009) y Laudato si' (LS) de Francisco (2015).

\section{FIGURA I. EI desarrollo humano integral en Populorum progressio}

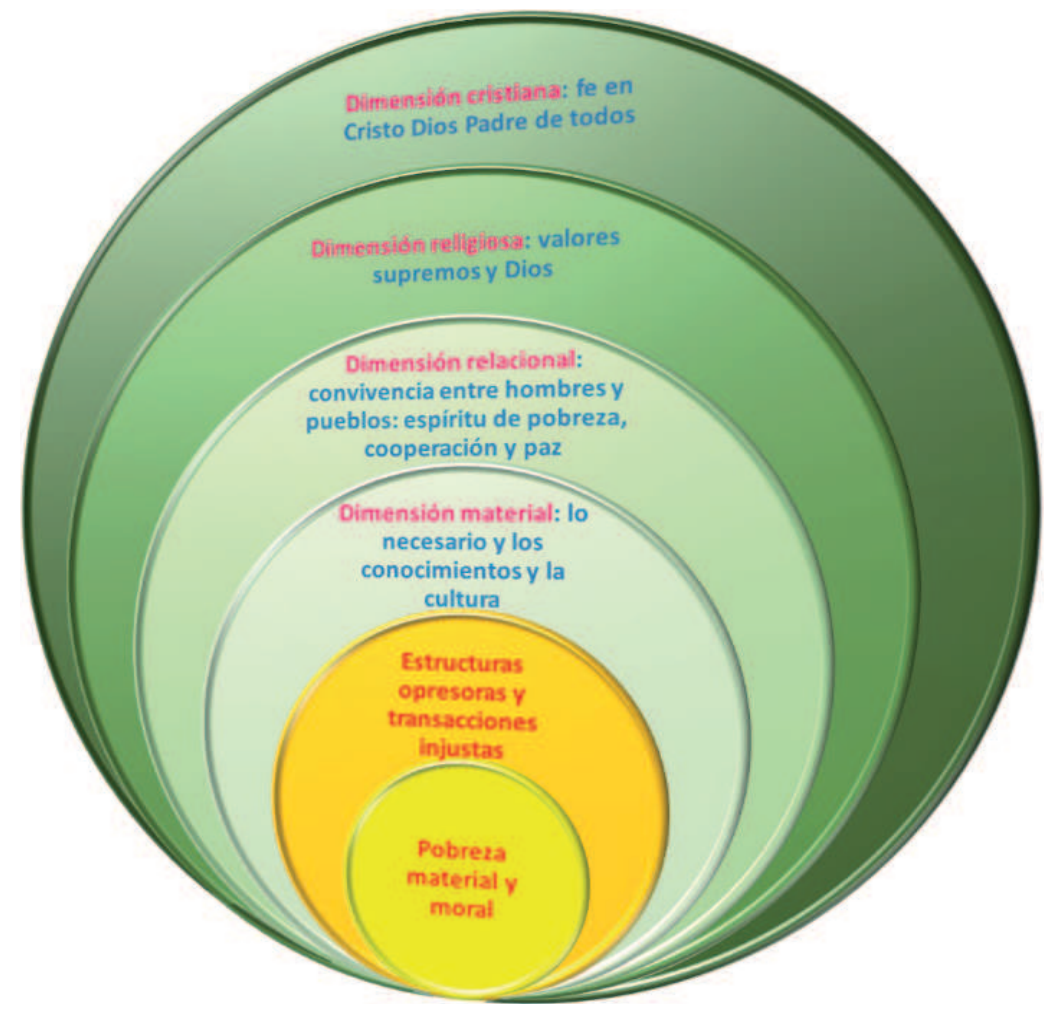

Fuente: elaboración propia. 
Si "la cuestión social" se "mundializó" con la MMy la PT de Juan XXIII, el desarrollo tomó carta de ciudadanía en la DSI con la PP de Pablo VI. En 2017 se conmemoró el 70 aniversario de dicha encíclica, en la que se afirma que el desarrollo debía afectar "a todo el hombre y a todos los hombres" (PP 14) y que era el paso de unas condiciones de vida menos humanas a otras más humanas (PP 20). La figura 1 sintetiza el paso de esas condiciones reduccionistas o menos humanas (pobreza material y moral debidas al egoísmo, estructuras opresoras y transacciones injustas por el abuso del tener o del poder) a las condiciones de vida más humanas que abarquen desde los bienes y servicios necesarios a los culturales, los espirituales y la cooperación, los valores, la trascendencia y la fe en el Dios cristiano.

Tras esta idea inicial, la DSI ha ido enriqueciendo el concepto de desarrollo con otras características diferenciales. Juan Pablo II pondrá el acento en la solidaridad mientras que Francisco ha extendido el desarrollo al entorno natural y a las generaciones futuras.

De forma somera, la escuela católica del desarrollo podría sintetizarse de la siguiente manera. El fenómeno del subdesarrollo es la falta de respuesta del hombre al proyecto trascedente de Dios sobre el hombre, que ha sido creado a imagen y semejanza suya. Esta naturaleza propia, le confiere el estatuto de persona que supera al individuo aislado y le hace un ser-en-relación, un ser social, con una dignidad intrínseca e igual entre hombre y mujer, una individualidad que le hace único e irrepetible, un fin en sí mismo. Además, la participación de todos los hombres creados en la redención de la humanidad operada en el Hijo de Dios, Jesucristo, hace que los hombres sean hechos hijos en el Hijo y hermanos entre sí, lo que configura un orden social de fraternidad universal. El modelo propio de desarrollo católico posee los siguientes rasgos constitutivos (Figura 2): 
FIGURA 2. Las características del modelo católico de desarrollo

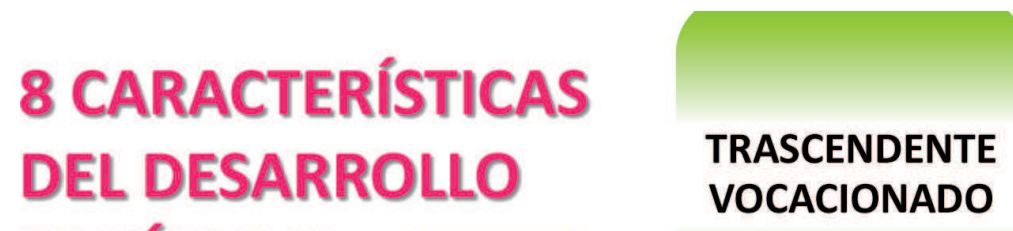
SEGÚN DSI

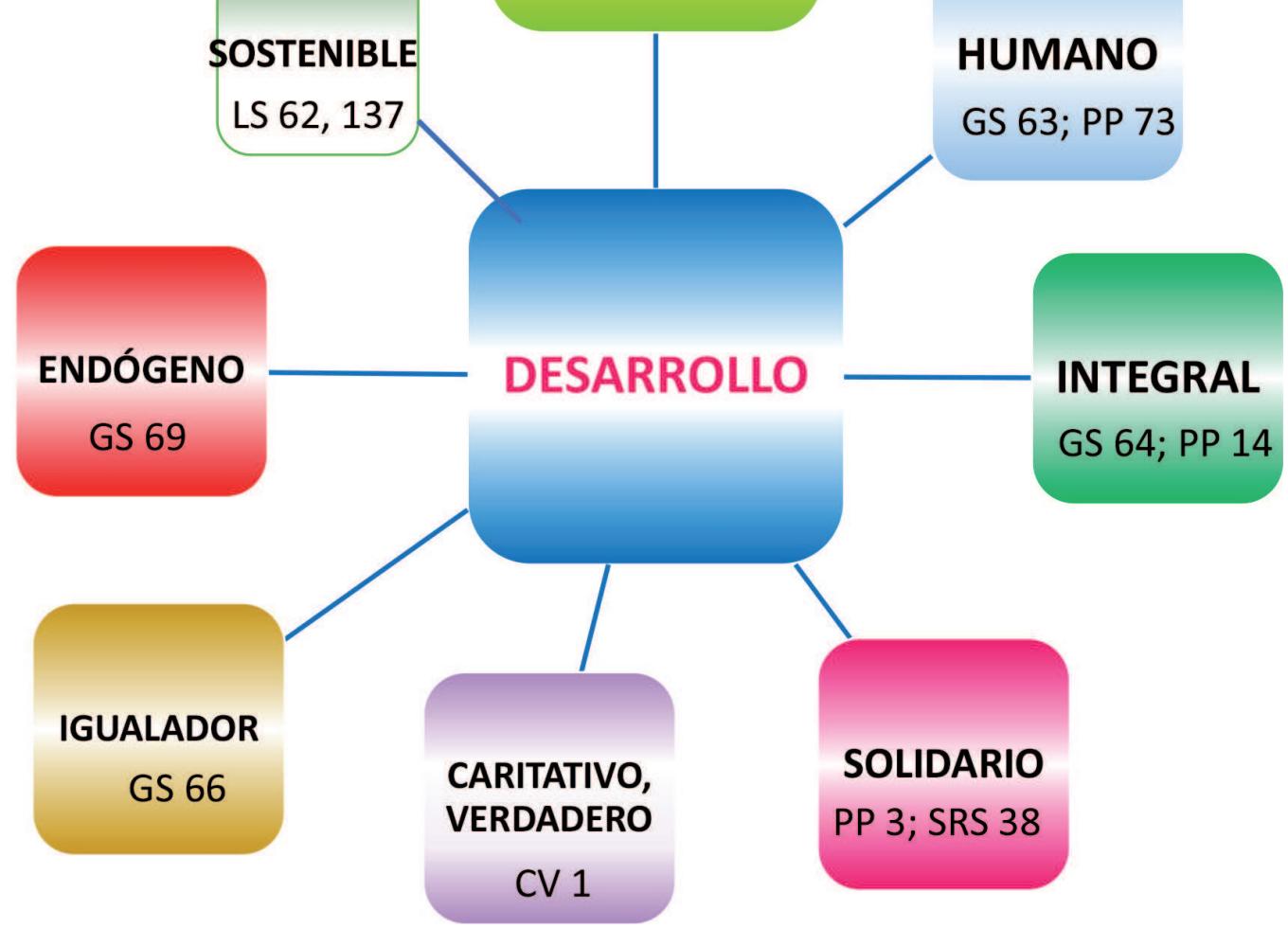

Fuente: elaboración propia.

i) Es un desarrollo trascendente pues el hombre no alcanza la verdad sobre sí mismo y en sus relaciones con los demás, si no es en el "espejo" de Jesucristo, quien comunicó al hombre su verdadera esencia y naturaleza (GS 22). Este rasgo se completa con una concepción del desarrollo vocacionado pues hombres y mujeres comparten la doble tarea originaria de señorear sobre las demás criaturas creadas por Dios y cultivar el jardín o huerto sobre el que Dios les puso $(G n 1,28)$, respetando la ley divina inserta en su conciencia (GS 16). Así, además de reconocer la llamada trascendente, reconocen que no pueden darse ellos mismos el sentido último de su existencia (CV 16) y que esa llamada requiere una respuesta libre y responsable por parte de cada uno (PP 15, 42, CV 16-17), respetando la verdad que dimana de Cristo (GS 22; CV 18). La 
trascendencia supone que acepta una fuente de conocimiento adicional a la razón, que es la revelación por la fe, de la dignidad de todo ser humano como "imagen y semejanza de Dios" (GS 12) y por tanto un modelo de sociedad basado en relaciones fraternas a imagen de un Dios que es comunidad en la Trinidad. Este rasgo de la trascendencia sólo es compartido por la escuela islamista de las identificadas por Hidalgo $(2011 a, b)$.

ii) Es un desarrollo humano pues el hombre debe ocupar el centro de la actividad productiva (GS 63) y esta debe estar siempre al servicio de la persona y no de la acumulación material (GS 64; PP 34). Pero su antropocentrismo no es "desviado" (LS 69, 118, 119, 122), sino que el hombre "debe respetar la bondad propia de cada criatura para evitar un uso desordenado de las cosas" (CIC 339). Es un antropocentrismo que reconoce las personas "son la principal riqueza de los países" (PNUD 2016) y acepta su teleología y ontología dentro del orden de la creación realizada por Dios. El desarrollo no debe ser "tan sólo económico, sino también humano" (PP 73). La escuela del desarrollo como capacidades, ampliando el inicial enfoque de las necesidades básicas y su derivada del desarrollo humano promovido por el Programa de Naciones Unidas desde 1990, comparten plenamente esta característica.

iii) Es un desarrollo integral tanto en el sentido de que debe alcanzar todas las dimensiones del ser humano (material, intelectual, moral, espiritual y religiosa, como sostiene GS 64), como a todos los hombres y pueblos. El enfoque de las capacidades también resalta los valores a la hora de determinar los modos de vida que cada persona elige para vivir y acepta que la religión pueda influir en estas valoraciones (Sen 1999; Alkire 2006; Deneulin \& Zampini Davies 2016).

iv) Es un desarrollo solidario en el que los hombres son corresponsables unos de otros (PP 3): debe alcanzar a todos los hombres y pueblos, no sólo por ser interdependientes -y cada vez más- en lo material y productivo o comercial, sino porque son una fraternidad que vive en un solo mundo donde las desigualdades injustas exigen el deber de compartir los bienes creados que han sido destinados a todos. Los pueblos ya desarrollados tienen "el deber gravísimo de ayudar a los pueblos que aún se desarrollan" (GS 81; PP 48). La solidaridad es entendida como "la determinación firme y perseverante de empeñarse por el bien común: es decir, por el bien de todos y de cada uno, para que todos seamos verdaderamente responsables de todos" (SRS 38). Esta interdependencia también es compartida por la escuela estructuralista y neoestructuralista-dependentista, aunque ella pone el acento en las negativas influencias-sobre todo comerciales- que se producen entre los países del centro y las periferias. 
v) Es un desarrollo caritativo-verdadero donde la caridad debe identificarse con el amor personal de Dios hacia cada uno de los seres humanos creados por Él. Es, por tanto, un rasgo ontológico. El hombre es creado para alcanzar "la realidad inteligible con verdadera certeza" y llegar a una sabiduría que le permite -por la fe- "contemplar y saborear el misterio del plan divino" gracias al don del Espíritu Santo (GS 15). Por eso, lejos de comprenderse como "excusa" que da de lo que le sobra y no cambia ninguna estructura injusta, la caridad es "la principal fuerza impulsora del auténtico desarrollo de cada persona y de toda la humanidad". Es "una fuerza extraordinaria, que mueve a las personas a comprometerse con valentía y generosidad en el campo de la justicia y de la paz" (CV 1). Por eso la caridad y la verdad han de ir siempre unidas pues, "la verdad es «lógos» que crea "diálogos» y, por tanto, comunicación y comunión" (CV 4). Este rasgo tampoco es compartido por ninguna de las escuelas identificadas por Hidalgo y sería una aportación propia del catolicismo.

vi) Es un desarrollo igualador (no igualitarista) ${ }^{6}$ en el que no caben desigualdades injustas entre clases (MM 73) o entre pueblos (GS 66) que aumentan sin cesar (MM73), debido a discriminaciones individuales y sociales. Respetando siempre la libre iniciativa personal y su debida remuneración, así como la legitimidad de la propiedad de lo logrado con su trabajo o inversión, se busca la distribución justa (MM 74) que garantiza el mínimo vital a todos los hombres pues, sin ello, no es posible la paz social (MM 157; PP 76; SRS 10). Esto implica que el solo mercado no es un instrumento autosuficiente que garantice el desarrollo (PP 58; EG 204). El desarrollo católico es redistribuidor pues quiere ser equitativo (PP 47; CV 37; EG 202-208). Este rasgo la aleja de las concepciones neoliberales y de algunas propuestas de la modernización. Se rechazan las "ideologías que defienden la autonomía absoluta de los mercados y la especulación financiera" (EG 56). En el desarrollo deben intervenir -en proporciones no específicas ni fijas para todo tiempo y lugar- el Estado, el mercado y la sociedad civil (CV $38)^{7}$.

"Es decir, no uniformador, sino en el sentido de "no dejar a nadie atrás" como propuso el informe previo del Grupo Abierto para los ODS (Naciones Unidas 2014) y recogió la Agenda 2030 de Desarrollo Sostenible (Naciones Unidas 2015) y el reciente Informe sobre el Desarrollo Humano (PNUD 2016).

7 Estas "proposiciones" necesitan muchos matices. Hay que huir de la simplificación que identifique el mercado como instrumento con la ideología liberal que excluya la necesidad de regulaciones por parte del Estado, tanto como del simplismo que identifique redistribución con intervención generalizada del Estado y negación de derechos de propiedad privada de la ideología comunista-neomarxista. La teoría económica convencional reconoce tanto fallos del Estado como del mercado. Sí podemos adelantar que la DSI admite el mercado como institución económica que facilita el encuentro entre personas para 
vii) Es un desarrollo endógeno pues se reconoce el papel insustituible del espíritu de iniciativa por parte de los propios países (PP 55; GS 86; SRS 44). "Siendo los pueblos, cada uno, los artífices de su propio desarrollo, los pueblos son sus primeros responsables. Mas no podrán realizarlo, aislados unos de otros" (PP 77).

viii) Es un desarrollo sostenible o de "ecología integral" (LS 62, 137), fruto de una relación de "señorío" del hombre sobre la naturaleza, que debe crecer en "conversión ecológica" (LS 216-221) mediante cambios en el estilo de vida (LS 203-208), diálogos eficaces, "honestos y transparentes" (LS 188) en todos los niveles relacionales (internacional, nacional, local, interreligioso entre la ciencia y la fe) como propone LS 164-201.

Estos rasgos estilizados deben completarse con muchos otros medios y orientaciones que la DSI ha ido ofreciendo a lo largo de los años y que ampliaremos a continuación.

Conviene advertir que la DSI no se entiende a sí misma como una tercera vía, alternativa a los sistemas económicos tradicionales de capitalismo y comunismo - las ideologías liberal y socialista (SRS 41; Sanz de Diego 1988). "La Iglesia no tiene soluciones técnicas que ofrecer al problema del subdesarrollo" (SRS 41), pero sí "tiene una palabra que decir...sobre la naturaleza, condiciones, exigencias y finalidades del verdadero desarrollo" (SRS 41). Como se profundiza a continuación, la DSI hace su aportación desde su estatuto de Teología Moral que comprende principios de acción y normas de juicio abiertas a la heterogeneidad de los contextos históricos, culturales y espaciales (OA 4; SRS 3, 8, 41) $)^{8}$. La Iglesia ofrece su modelo de desarrollo humano porque cumple así su misión evangelizadora (Congregación para la Doctrina de la Fe 1986; SRS 41). El precedente de la reflexión teológico moral y del derecho que hicieron los autores católicos de la Escuela de Salamanca, puede dar una idea de cómo la Teología aplicada a las realidades de los problemas contemporáneos del desarrollo, puede ser una fuente de avance y desarrollo de los pueblos. La teología del siglo XVI español se ocupó de problemas económicos como la teoría del valor y del precio, la integración de

realizar sus contratos e intercambios libres, donde debe reinar la confianza mutua y la justicia, ordenada al logro del bien común (CA 42). El modelo de desarrollo católico será "con mercados" pero no identificado con los supuestos neoliberales, al igual que tampoco con el modelo colectivista exsoviético.

${ }^{8}$ La Congregación para la Educación Católica (1988:3c) refuerza el nexo de la naturaleza ética de "los principios siempre válidos", con los "juicios contingentes" en función de las circunstancias cambiantes de la historia. Pero el enfoque ético nunca debe suponer "descuidar los aspectos técnicos de los problemas". 
la teoría monetaria con la general de los precios, la teoría cuantitativa del dinero, el sistema tributario, una teoría de los cambios y otra del interés, entre otros, al analizar en profundidad problemas éticos como el precio justo, la usura o las cargas tributarias (Grice-Hutchinson 1989).

\section{Rasgos característicos en las dimensiones del desarrollo humano integral}

Es conveniente caracterizar las dimensiones propias del proceso de desarrollo humano integral, pues el desarrollo tiende a concebirse de forma economicista, mecanicista y, a menudo, reducido al crecimiento económico cuando, en realidad, es un proceso dinámico y multidimensional. Hay consenso en que las dimensiones del desarrollo son: política, económica, social, cultural y medioambiental. Podemos seleccionar los siguientes rasgos diferenciales en cada una de ellas, para resaltar la aportación que realiza la "escuela católica de desarrollo" en la promoción de sociedades más justas y equitativas (Figura 3).

En la dimensión política, se pueden resaltar tres rasgos fundamentales de la aportación católica. En primer lugar, la concepción de la autoridad como renuncia a todo poder coactivo y ejercida como servicio a los demás, fruto de la profunda experiencia de Dios como Abbá, que tuvo Jesús de Nazaret. Esta concepción del poder, debe ser ejercida tanto en el campo civil de los políticos democráticamente elegidos como representantes sobre los ciudadanos, como hacia dentro de la Iglesia?.

En segundo lugar, el conjunto de los principios doctrinales de la enseñanza social de la lglesia conforma un modelo social en el que es posible la variedad de partidos políticos, siempre que éstos no defiendan una ideología totalitaria o contraria a la dignidad humana. La vigilancia de la separación de poderes y del deber de que el Estado cumpla con su función de garantizar y buscar activamente el bien común, debe ser llevada a cabo de forma activa por la sociedad civil, tanto en su vertiente organizada como espontánea. Esto implica un modelo de "controles y balances" del poder entre el Estado, los agentes no estatales y las instituciones independientes creadas para dicho fin (desde los tribunales de justicia, hasta las comisiones de defensa de la competencia, de los consumidores o el banco central).

\footnotetext{
9 En este sentido, el mejor título para el papa sería "siervo de los siervos de Dios" empleado por Gregorio I (590-604) frente al arzobispo de Constantinopla Juan el Ayunador que se denominó "Patriarca ecuménico". Suele emplearse al comienzo de las bulas.
} 


\section{FIGURA 3. Aportaciones diferenciales de la DSI a las dimensiones del desarrollo}

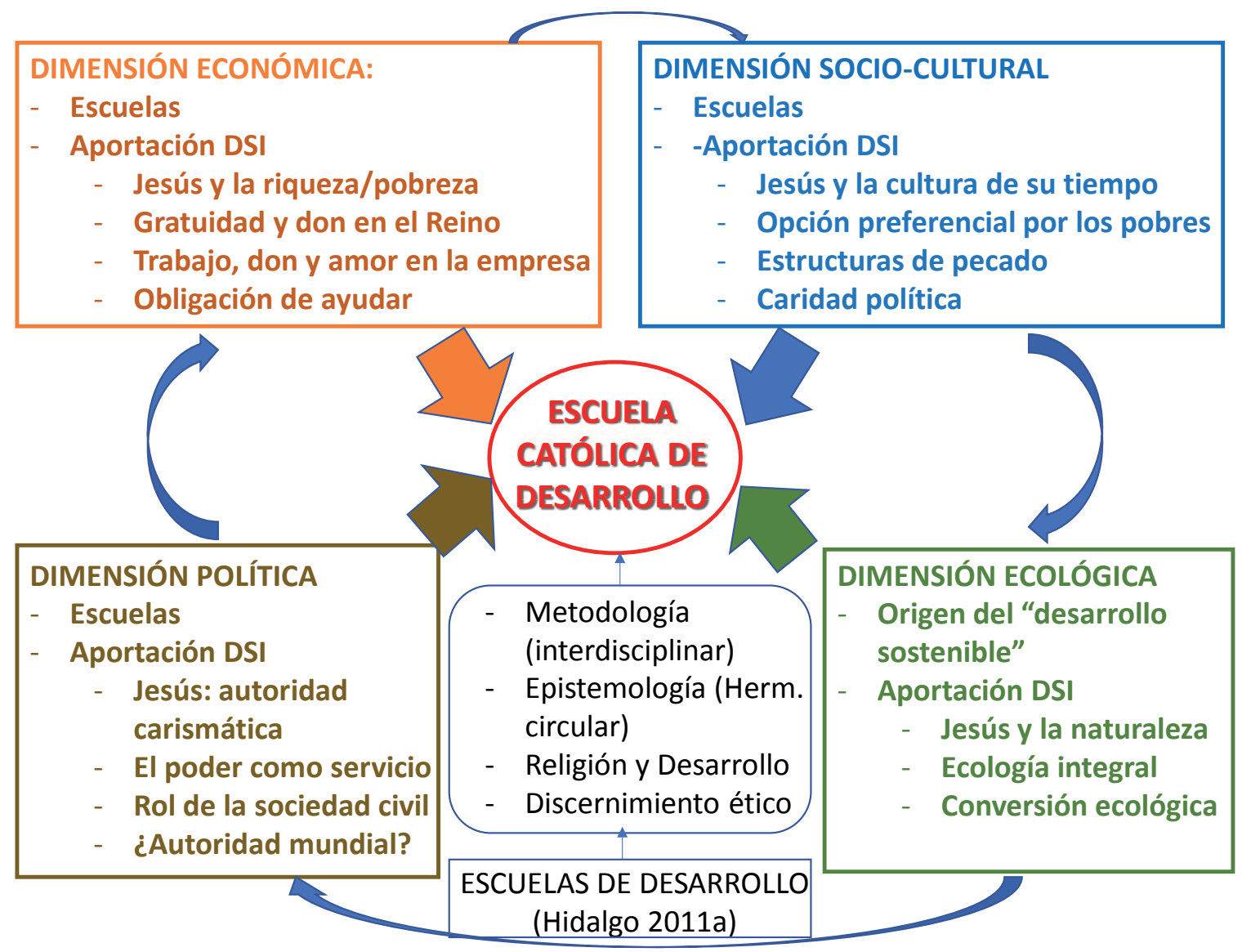

Fuente: elaboración propia.

Por último, ante las crecientes interdependencias y necesidad de acceso universal a los "bienes comunes globales" (LS 174), podría ser conveniente disponer de una autoridad supranacional que, respetando el principio de subsidiariedad, pueda tener legitimidad para garantizar dicho acceso y, si fuera necesario, penalizar el incumplimiento de acuerdos globales o la generación de externalidades negativas a quienes las cometan.

La concepción orgánica de la sociedad que defiende la Iglesia, la acerca al enfoque de las capacidades, al Enfoque Basado en Derechos Humanos y a ciertos aspectos de la Escuela Neoinstitucionalista. La Iglesia puede y debe aplicarse ella misma los principios de subsidiariedad y participación "ad intra", inspirándose en la Trinidad como fuente de toda comunión basada en el amor de caridad. La 
Iglesia podría desempeñar un valioso papel internacional de multilateralismo moral en favor de los pobres y desfavorecidos en los foros internacionales donde tiene representación como miembro invitado.

Por lo que respecta a la dimensión económica, conviene hacer hincapié en la imprescindible incorporación de la Ética a la Economía y cómo el concepto de "persona" es mucho más amplio y completo que el de "individuo" que actúa racionalmente sólo si maximiza sus utilidades inmediatas y materiales. En la concepción individualista, las externalidades comunitarias (positivas y negativas) no son tenidas en cuenta.

La DSI enfoca la producción, la técnica, la propiedad y la distribución económica siempre al servicio del hombre integral, centro del desarrollo. Jesús remarcó el carácter de medio para fines superiores de la riqueza y avisó de los peligros derivados para el hombre cuando ésta ocupa el lugar central de su vida. Las palabras y gestos de Jesús de Nazaret transparentaron una vida bajo la lógica del don que, partiendo de la gratuidad que supone nacer criatura receptora de amor incondicional del Padre, incorpora también la tarea de vivir conforme a la "caridad en la verdad".

Ejemplos de lógica del don pueden ser la autodonación recíproca matrimonial, el ejercicio del sacerdocio mediador de Jesús y el perdón como muestra de la misericordia divina. Al aplicar esa lógica "personalista" y trinitaria del don a las relaciones laborales, queda resaltada la normatividad de que el trabajo prime sobre el capital, el trabajo subjetivo sobre el objetivo, la inclusión de derechos laborales (como la huelga) y una manifestación tan esencial en la DSI como es practicar el salario justo $^{10}$.

Además, es posible mostrar cómo en la empresa pueden vivirse relaciones desde el amor de donación, donde se superan los resultados de la "lógica de las virtudes" en el plano extrínseco, intrínseco y trascendental. Las relaciones de amor por motivación extrínseca responden al interés y beneficio mutuo. Las intrínsecas, muestran la capacidad de alcanzar relaciones de amistad entre algunos compañeros, donde se realizan acciones de búsqueda del bien del otro de forma recíproca. Las tras-

\footnotetext{
${ }^{10}$ Conviene recordar las condiciones que señaló Juan XXIII en MM 71 que integran el salario justo: i) que permita a los trabajadores mantener un nivel de vida y digno a ellos y sus familiares; ii) que tenga en cuenta la efectiva aportación de cada trabajador al proceso productivo (su productividad); iii) la situación financiera de la empresa; iv) el bien común nacional sobre todo en lo relacionado al empleo, y v) el bien común universal y de cada país en función de su extensión y los recursos de que disponga.
} 
cendentales son las de la lógica del don en el sentido de que se busca practicar el amor de benevolencia sin reciprocidad y únicamente por hacer crecer a la otra persona. Por ejemplo, si alguien invierte en un negocio de un familiar porque está convencido de que eso ayuda a la realización de la vocación de ese familiar, sin esperar ningún retorno ni rédito.

Por último, conviene recordar la obligación repetida por la DSI de que los pueblos más desarrollados ayuden a los que están en vías de desarrollo, especialmente a través de formas de financiación que incluyan cierto grado de donación, como la ayuda oficial al desarrollo, cuya necesidad ha quedado renovada en la III Conferencia Internacional de Financiación del Desarrollo de julio de 2015 (Naciones Unidas $2015 \mathrm{~b}$ ) y teniendo en cuenta los criterios de eficacia señalados por Benedicto $\mathrm{XVI}$ en CV 47, como la trasparencia, progresión en los procesos, la participación efectiva de los beneficiarios en los proyectos, el acompañamiento y seguimiento de resultados, dado que no hay recetas universalmente válidas.

Por lo que respecta a la dimensión sociocultural del desarrollo, si las escuelas de desarrollo basadas en la modernización y la neoliberal han tendido a ignorar esta dimensión por su concepción limitada del hombre como agente económico de preferencias estáticas, esto puede estarse paliando en la actualidad a través de las investigaciones de la "economía del comportamiento" (behavioural economics) que acepta funciones de comportamiento, tanto personal como grupal, basadas en preferencias dinámicas y mediadas culturalmente (Hoff \& Stiglitz 2010, 2016). Por su parte, las escuelas estructuralista y neomarxista integraron la "estructura social" en sus análisis y fueron capaces de denunciar los efectos negativos de algunas de ellas como causas de subdesarrollo y de la exclusión social (la "infraestructura" o base material, la "superestructura" o formas jurídicas, políticas y artísticas, religiosas y filosóficas de cada momento histórico que quedan en función de los intereses y grupos dominantes, o la "plusvalía").

La DSI, ha afirmado que la dimensión cultural del hombre es una cuestión ontológica. La Iglesia postconciliar reconoce el pluralismo cultural como obra del Espíritu Santo "presente en todas las culturas" (Redemptoris Missio 29). No se puede ser humano ignorando esa verdad. Como la cultura aporta tres funciones al hombre -epistemológica, identitaria y nómica (Tornos 2001)-, el hombre conoce, se reconoce y valora de forma cultural. Por eso es importante rechazar las propuestas de desarrollo que supongan discriminaciones que pueden sufrir las personas 0 grupos debido a las diferencias culturales o étnicas (Besley et al. 2011), así como tener en cuenta las "desigualdades horizontales" (Stewart et al. 2005). 
Jesús mismo nació, creció y se humanizó como hombre cultural y, sin realizar una revolución cultural violenta, generó con su predicación y sus signos de fe, una liberación de costumbres y estructuras que oprimían a numerosos colectivos marginados, fruto del legalismo o del sistema de poder imperante" ${ }^{11}$. Jesús no asumió de forma conformista y acrítica las tradiciones culturales de su tiempo y tampoco centró su obrar y predicar en un cambio de modelo cultural que trajera el desarrollo a través de la subversión de las costumbres, lenguaje, instituciones y estructuras de convivencia social. Pero, al no hacer acepción de personas y admitir en su seguimiento a toda clase de personas, incluyendo a grupos marginados como las mujeres, los niños, los pecadores o enfermos, actuó de forma contracultural. En su grupo había zelotes, fariseos, publicanos y pescadores. Todo el que quería oír su palabra liberadora podía hacerlo y seguirlo. Prolongando este enfoque, la "libertad cultural" fue norma de conducta que mantuvieron las primeras comunidades cristianas, no sin diferencias o desencuentros entre ellas (Aguirre 2016).

Otro de los rasgos propios del modelo católico de desarrollo es la constante "opción preferencial por los pobres" en la tradición eclesial, como categoría irrenunciable que muestra el carácter social y cultural -y no sólo económico- de la pobreza (Puebla 1134, 1153-1155; SRS 42b; CA 11, 57; EG 200; Boff 1980; González Faus 2005; Gutiérrez 2007) ${ }^{12}$.

Por ideología o por inercia cultural, existen las denominadas "estructuras de pecado": aquellas formas de participación en el mal, que se ocultan tras actos humanos, pero que engendran subdesarrollo y exclusión social (SRS 36-40). Juan Pablo II las identificó con "el exclusivo afán de ganancia" y "la sed de poder" (SRS 36a) y Francisco ve en ellas una "globalización de la indiferencia" (EG 53). Frente a ellas, los actos regidos por la "caridad política" (DCE 29; CV 7; CDSI 581), conducen a su transformación, superando el individualismo y un sentido pervertido de la "caridad" como "limosnas asistencialistas" (EG 204). No se puede desligar la fe de la lucha por la justicia. La "escuela católica de desarrollo" exige a todos un

1 En palabras de Küng (2015:44): "Jesús, así como no fue un hombre del sistema, tampoco fue un revolucionario sociopolítico".

12 La opción no es excluyente, pues es cristológica (Aparecida 146) y "nos pide dedicar tiempo a los pobres, prestarles una amable atención, escucharlos con interés, acompañarlos en los momentos difíciles, eligiéndolos para compartir horas, semanas o años de nuestra vida, y buscando desde ellos, la transformación de su situación" (Aparecida 397). "Sólo la cercanía que nos hace amigos, nos permite apreciar profundamente los valores de los pobres de hoy, sus legítimos anhelos y su modo propio de vivir la fe. La opción por los pobres debe conducirnos a la amistad con los pobres" (Aparecida 398). 
compromiso activo con la "caridad política", cada uno según su vocación (CV 7). Las acciones basadas en esta caridad, transforman las "estructuras de pecado" que oprimen sobre todo a los más pobres, en "estructuras de amor" y construyen una civilización del amor (ChL 42; González-Carvajal 2004, 2005).

Por último, en la dimensión ecológica se ha venido insistiendo en que cuidar de la "casa común" no es ya una opción más, sino que la "cuestión social" inicial de $\mathrm{RN}$, tras hacerse internacional en la PP, se ha convertido en la "cuestión ecológica" con LS. Ésta reclama un "cuidado necesario" (Boff 2012), es un imperativo (Jonas 1995). Los cristianos deben actuar y vivir de forma que "los cielos nuevos y la tierra nueva en donde la habite la justicia" $(2 \mathrm{Pe} 3,13)$ sean complementarios, porque "todo está conectado" como tanto repite LS.

La encíclica de Francisco resalta la necesidad del diálogo multidisciplinar, los cambios personales hacia un estilo de vida menos consumista y más responsable con el medioambiente, o combatir la "cultura del descarte" (EG 53) con acciones incluyentes propias de la "ecología integral" que rompen la "lógica de la violencia, del aprovechamiento, del egoísmo" (LS 230). Francisco advierte de dos amenazas clave para el desarrollo ecológico integral: el paradigma tecnocrático (EG 106) y el "antropocentrismo desviado" (LS 118), que han conducido a un "superdesarrollo" (CV 22; LS 109) que es criticado y compartido por algunos autores defensores del "postdesarrollo" (Escobar 2010; Unceta 2014) o del "transdesarrollo" (CubilloGuevara \& Hidalgo-Capitán 2015).

Francisco también enfatiza la relación armónica de Jesús con la naturaleza (LS 98) y eso conduce a las implicaciones cristológicas del "continuum" creación-encarnación-salvación como culmen de todo "en, por y para Cristo". Ese es el fundamento de un verdadero desarrollo sostenible: la "ecología integral" 13 que "nos conecta con la esencia de lo humano" (LS 11) y la necesidad de la "conversión ecológica" duradera y comunitaria (LS 219), ante las estructuras de pecado que degradan el ambiente.

${ }^{13} \mathrm{O}$ incluso "ecología humana" como usó en el Discurso a los participantes de la XXIV Asamblea General de la Pontifica Academia para la Vida (25.06.2018). 


\section{Conclusiones y consideraciones finales}

El 1 de enero de 2017 entraba en vigor el Motu Proprio por el que el Papa Francisco creaba el Dicasterio para el Servicio del Desarrollo Humano Integral ${ }^{14}$. Este Dicasterio asumió las competencias del Consejo Pontificio Justicia y Paz, el Consejo Pontificio "Cor unum», el Consejo Pontificio para la Pastoral de los Emigrantes e Itinerantes y el Consejo Pontificio para la Pastoral de la Salud. La elección del nombre "Desarrollo Humano Integral" es ya una señal de qué concepto de desarrollo se tiene desde la Iglesia católica. En este trabajo hemos querido caracterizarlo un poco más recorriendo sus dimensiones política, económica, sociocultural y ecológica.

Por otra parte, el 4 de abril de 2017, en el discurso dirigido a los participantes en el Congreso Internacional con motivo del 50 aniversario de la Populorum progressio, Francisco señaló la centralidad de la persona en el modelo de desarrollo:

el concepto de persona, nacido y madurado en el cristianismo, contribuye a perseguir un desarrollo plenamente humano. Porque persona siempre dice relación, no individualismo, afirma la inclusión y no la exclusión, la dignidad única e inviolable y no la explotación, la libertad y no la coacción.

A su vez, Naciones Unidas ha concebido para su Agenda 2030 de Desarrollo Humano Sostenible un modelo de "5 P" (Naciones Unidas 2015:2): personas, prosperidad, planeta, paz y "partenariados" (o alianzas en la versión española).

Vemos que existen ciertas convergencias en las propuestas y que "las personas son la principal riqueza de los pueblos" (PNUD 2016) en contraposición al paradigma más clásico de confiarlo todo al crecimiento económico (PP 14, 50; EG 54). Es necesario completar el crecimiento con la distribución equitativa, el trabajo y la promoción integral de los pobres superando el mero asistencialismo (EG 204).

Partiendo del estatuto epistemológico desde donde deben interpretarse las orientaciones de la DSI (el diálogo entre la fe y la razón; la caridad y la verdad que generan "diálogos de comunión", CV 4; una circularidad hermenéutica permanente entre la revelación y la autonomía de la realidad reconocida en GS 36) y de justificar que la religión puede ser una de las dimensiones y voces del desarrollo humano como

\footnotetext{
${ }^{14}$ Motu Proprio "Humanan progressionem" del 17 de agosto de 2016 (http://w2.vatican.va/content/ francesco/es/motu_proprio/documents/papa-francesco-motu-proprio_20160817_humanamprogressionem.html) y su correspondiente estatuto de la misma fecha: "Statutes of the dicastery for promoting integral human development" http://w2.vatican.va/content/francesco/en/motu_proprio/ documents/papa-francesco_20160817_statuto-dicastero-servizio-sviluppo-umano-integrale.pdf (Acceso 05/04/2017).
} 
han mostrado Deneulin \& Bano (2009), se identificaron ocho rasgos característicos del modelo católico de desarrollo: trascedente y vocacionado, humano, integral, solidario, verdadero-caritativo, igualador, endógeno y sostenible.

Si aceptamos el esquema propuesto por Hidalgo $(2011$ la) para delimitar las siete escuelas de desarrollo identificables desde la Economía Política del Desarrollo, podríamos sintetizar la escuela católica de desarrollo siguiendo sus mismos ítems.

La concepción del desarrollo es el proceso mediante el que las personas, intrínsecamente dignas y sujetos de derechos, logran las condiciones de vida que les permiten el logro de su propia perfección. Por el contrario, el subdesarrollo está causado por la insolidaridad, la inequidad, las relaciones de dominio neocolonial, la dependencia de países en desarrollo hacia la tecnología., la dependencia comercial, "el exclusivo afán de ganancia y la sed de poder", el "paradigma tecnocrático" y un "antropocentrismo desviado".

Variable clave en el proceso de desarrollo es el bien común (no el PIB), entendido este como las condiciones de vida que permiten la plena realización de todos y cada uno de los miembros de la sociedad. Es más que la suma simple de los intereses individuales.

La estrategia política para el desarrollo es qquella que permite la participación de todos en la sociedad, bajo el principio de subsidiariedad, respetando el pluralismo partidista y las ideologías, siempre que no se conculque la dignidad personal. La democracia es un buen sistema de participación pero no es perfecto. Es importante el respeto a los DDHH incluido el de la libertad religiosa.

El proceso de desarrollo se manifiesta en la expansión de las condiciones sociales que permiten a todos y cada uno, personas y pueblos, lograr su propia perfección de forma integral. Es el camino histórico de salvación hacia el Reino de Dios.

En cuanto a la financiación del desarrollo, es obligación de los países desarrollados de ayudar a los que están desarrollo con una parte de donaciones.

Por lo que respecta a la tesis del beneficio mutuo en relaciones internacionales, puede darse, pero también se denuncian la asimetría de poder y falta de representación, voz y participación de los pobres en los procedimientos de decisión y en los Organismos Internacionales. A semejanza de Jesús, es nuclear optar preferente por ellos. 
La DSI no admite una sola economía (tesis de la monoeconomía en Hidalgo); no se pronuncia sobre teorías económicas concretas, pero rechaza el dominio absoluto del mercado o su "auto-regulación". El Estado convive y regula el mercado. Debe combinarse una relación entre variables económicas y no económicas. La economía no es la única dimensión del desarrollo. La política, la social, la cultural y la ecológica son dimensiones igual de relevantes. La política y la economía deben estar al servicio de la persona y del bien común.

Desde luego, una conclusión que emana de este trabajo es que la mayor cercanía entre las escuelas de desarrollo y la católica, se produce con el enfoque de las capacidades y del desarrollo humano. Si bien ambas se basan en valores y ponen a la persona en el centro entendiendo el desarrollo de forma integral y no economicista (como lo hicieron la escuela de la modernización y la neoliberal extrema), la antropología de la DSI, por su carácter trascendente (compartido por la escuela islamista) y la concreción en los valores y mandatos de "caridad en la verdad" tal como las transmitió Jesús, son de una riqueza que nos parece superior a lo llevado a cabo hasta ahora por el paradigma del desarrollo humano sostenible o por la escuela neoinstitucionalista.

Si el "enfoque de las capacidades" acierta al entender el desarrollo como las formas de ser y hacer en la vida lo que se considera razonadamente valioso, no ha llegado a concretar una antropología como la católica donde el ser se identifica con persona (relacional e imagen de Dios) y el hacer como el trabajo subjetivo donde el hombre se humaniza a sí mismo. En lo católica, hay jerarquía de valores: la caridad y de ella, la verdad, la libertad, la justicia y-como fruto-la paz (PT 37).

Dado que "la realidad es superior a la idea" (LS 201), el diálogo "honesto y transparente" (LS 188) entre escuelas, puede nutrirse de "una pluralidad armónica de itinerarios y de estilos que se crucen entre sí en la unicidad de la persona" (Ravasi $2014)^{15}$. Sería conveniente que este diálogo fecundo y mutuamente enriquecedor pudiera influir de forma efectiva y creativa en la consecución de la Agenda 2030 de Desarrollo Sostenible.

${ }^{15}$ Citado en Martínez (2015:30). 


\section{Referencias}

AcostA, A. (2013) El buen vivir. Sumak Kawsay, Una oportunidad para imaginar oros mundos, Barcelona, Icaria.

AgUIRRE, R. (2016) "Las primeras comunidades en su diversidad", en AA. VV., La Iglesia en una Sociedad Postmoderna, Valencia, Tirant Humanidades, 117-143.

AlkiRe, S. (2006) "Religion and Development", en Clarke, D. A. (ed.) The Elgar Companion to Development Studies, Cheltenham, Edward Elgar, 502-509.

Besley, T. J., García-Montalvo, J. y Reynal-Querol, M. (2011) “Do Educated Leaders Matter?", The Economic Journal 121(554), 205-227.

Boff, L. (1980) "Teología de la liberación: La opción preferencial por los pobres", Salmanticensis 27(2), 247-260.

- (2012) El cuidado necesario, Madrid, Trotta.

BRAÑA, F.J. (2016) "El pensamiento desarrollista y neodesarrollista en América Latina y el Buen Vivir: continuidades y cambios" en BRAÑA, F. J., DOMínguez, R. Y LEón, M. (eds.) (2016) Buen vivir y cambio de la matriz productiva. Reflexiones desde el Ecuador, Quito, Friedrich-Ebert-Stiftung (FES-ILDIS), Cap. 1, 15-83.

BrUNI, L. (coord.) (2001) Economía de comunión. Por una cultura económica centrada en la persona, Madrid, Ciudad Nueva.

Comisión Europea (2015) Cerrar el círculo: un plan de acción de la UE para la economía circular. $\operatorname{COM(2015)~} 614$ final. Bruselas, 2-12-2015.

Comisión TeOlóGICA Internacional (2012) Teología hoy: perspectivas, principios y criterios, Madrid, BAC.

CONGREGación PARA LA DOCTRINA DE LA FE (1986) Instrucción sobre libertad cristiana y liberación, Libertatis conscientia, Madrid, BAC.

Cubillo-Guevara, A. P. y Hidalgo-Captín, A. L. (2015) "El trans-desarrollo como manifestación de la trans-modernidad. Más allá de la subsistencia, el desarrollo y el post-desarrollo", Revista de Economía Mundial 41, 127-158. 
Deneulin, S. y BANO, M. (2009) Religion in Development: Rewriting the Secular Script, Londres, Zed Books.

Deneulin, S. y ZampinI DaVIeS, A., (2016) "Theology and development as capability expansion", HTS Teologiese Studies/ Theological Studies 72(4), a3230.

Escobar, A. (2010) "América Latina en la encrucijada: ¿̇modernizaciones alternativas, postliberalismo o postdesarrollo?", en BRETON, V. (ed.) Saturno devora a sus hijos, Barcelona, Icaria, 33-85.

Felber, Ch. (2012) La economía del bien común, Bilbao, Deusto.

González-Carvajal, L. (2004) "La caridad política, de ayer a hoy", Corintios XIII $110,145-161$.

- (2005) "Las estructuras de pecado y la caridad política", en ÁvILA, A. (ed.) El grito de los excluidos. Homenaje a Julio Lois, Estella, Verbo Divino, 341-359.

GRICE-HUTCHINSON, M. (1989) "El concepto de la Escuela de Salamanca: sus orígenes y su desarrollo", Revista de Historia Económica 7(2), 21-26.

GutiéRrez, G. (2007) "La opción preferencial por el pobre en Aparecida", La Cuestión Social 15(4), 371-388.

HIDALGO, A. L. (201 1) “Economía política del desarrollo. La construcción retrospectiva de una especialidad académica", Revista de Economía Mundial 28, 279-320.

- (201 1b) "La escuela islamista de la economía política del desarrollo" UNISCI Discussion Papers 26.

Hoff, K. y Stigltz, J. (2010) “Equilibrium Fictions: A Cognitive Approach to Societal Rigidity", American Economic Review 100(2),141-146.

- (2016) "Striving for Balance in Economics. Towards a Theory of the Social Determination of Behavior", NBER Working Paper 7537, Cambridge.

JONAS, H. (1995) El principio de responsabilidad. Ensayo de una ética para la civilización tecnológica, Barcelona, Herder.

KüNG, H. (2015) Jesús, Madrid, Trotta. 
LATOUCHE, S. (2008) La apuesta por el decrecimiento. ¿Cómo salir del imaginario dominante?, Barcelona, Icaria.

Martínez, J. L. (2015) "Laudato si' y la cuestión socio-ambiental", en SANz GiméNEZ-RICO, E. (ed.) Cuidar de la tierra, cuidar de los pobres. Laudato si' desde la teología y con la ciencia, Santander, Sal Terrae, Cap. 1, 23-49.

NACIONES UNIDAS (2015) "Transformar nuestro mundo: la Agenda 2030 para el Desarrollo Sostenible", A/69/L.85.

- (2015b) "Documento final de la Tercera Conferencia Internacional sobre Financiación para el Desarrollo: Agenda de Acción de Addis Abeba", A/CONF.227/L. 1 . Nueva York.

Nussbaum, M. (2012) Crear Capacidades. Propuesta para el desarrollo humano, Barcelona, Espasa Libros.

PAUL, G. (2011) La economía azul, Barcelona, Tusquets.

PNUD (2016) Informe sobre el Desarrollo Humano 2016. Desarrollo humano para todos. Programa de Naciones Unidas para el Desarrollo. Nueva York.

RAVASI, G. (2014) Discurso de aceptación del Doctorado honoris causa, Universidad de Deusto, 4 de marzo. Deusto.

SANZ de Diego, R. (1988) "Ni ideología ni 'Tercera Vía', Doctrina para la acción. El por qué de la encíclica", Revista de Fomento Social 172, 345-368.

SELINGER, L. (2004) "The Forgotten Factor: The Uneasy Relationship between Religion and Development", Social Compass 51(4), 523-543.

SEN, A. K. (1999) Development as Freedom, Nueva York, Anchor Books.

SteWART, F., Brown, G. y MANCINI, L. (2005) "Why Horizontal Inequalities Matter: Some Implications for Measurement", CRISE Working Paper 19. Oxford.

Sundararajan, A. (2017) The Sharing Economy, the End of Employment and the Rise of Crowd-based Capitalism, Cambridge, MIT Press.

TAIBO, C. (2009) En defensa del decrecimiento: Sobre capitalismo, crisis y barbarie, Madrid, Los Libros de La Catarata. 
Ter HAAR, G. y Elus, S. (2006) "The Role of Religion in Development: Towards a New Relationship between the European Union and Africa", European Journal of Development Research 18(3), 351-367.

TomalIN, E. (ed.) (2015) The Routledge Handbook of Religions and Global Development, Londres, Routledge.

TORNOS, A. (2001) Inculturación. Teología y método, Madrid y Bilbao, Universidad Pontificia de Comillas y Desclée de Brouwer.

UNCETA, K. (2014) Desarrollo, postcrecimiento y Buen Vivir: Debates e interrogantes, Quito, AbyaYala.

VAN TIL, K. A. (2010) "Poverty and Morality in Christianity", en Galston, W. A. y Hoffenberg, P. H. (eds.) Poverty and Morality. Religious and Secular Perspectives. Nueva York, Cambridge University Press, Cap. 4, 62-82.

Ver BeEK, K. A. (2000) "Spirituality: A Development Taboo", Development in Practice $10(1), 31-43$.

Webster, K. (2016) The Circular Economy: A Wealth of Flows. Ellen MacArthur Foundation Publishing.

Zamagn, S. (2014) Por una economía del bien común, Madrid, Ciudad Nueva. 